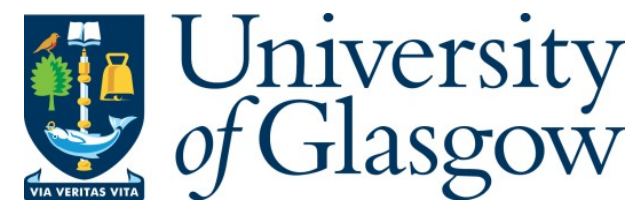

Green, Todd, and Erickson, Kris (2014) For those playing along at home: four perspectives on shared intellectual property in television production. Journal of Media Business Studies, 11 (2). pp. 2-24. ISSN $1652-2354$

Copyright (C 2014 JIBS MMT Centre

A copy can be downloaded for personal non-commercial research or study, without prior permission or charge

Content must not be changed in any way or reproduced in any format or medium without the formal permission of the copyright holder(s)

When referring to this work, full bibliographic details must be given

http://eprints.gla.ac.uk/94549/

Deposited on: 25 June 2014

Enlighten - Research publications by members of the University of Glasgow http://eprints.gla.ac.uk 


\title{
For those playing along at home: four perspectives on shared intellectual property in television production
}

\author{
Todd Green \\ Head of Genre Support, FremantleMedia \\ Business Manager, King \\ toddmgreen@gmail.com \\ Dr. Kris Erickson \\ Adam Smith Research Fellow, \\ School of Law, University of Glasgow \\ Kristofer.Erickson@glasgow.ac.uk
}

Submitted to Journal of Media Business Studies $7^{\text {th }}$ May, 2014

\begin{abstract}
Television audiences and fans are increasingly enrolled in the coproduction of the television experience. Return-path communication enabled by digital media allows show producers to gather real-time market data about audiences, as well as to solicit creative input from audience members individually and in aggregate. This transformation is not without its challenges: audiences and producers must negotiate shared ownership of the televisual product. The intellectual property implications of interactive TV are therefore considerable: who owns the intellectual property in shows with substantial audience engagement? How can we locate and ascertain the value of intellectual property added by viewer contributions? The authors propose four definitions of intellectual property through which to examine the status of viewer creativity: legal/regulatory, entrepreneurial, accounting and communitarian. The authors conclude that each definition on its own is insufficient to aid strategic planning, so a new model of programme-as-platform is proposed for TV companies working with interactive IP.
\end{abstract}




\section{Introduction}

It is apparent from a range of recent interventions by media scholars that something profound is happening to television. Despite the need for caution when deploying terminology such as 'interactivity', there is a widespread consensus that we are witnessing something akin to an interactive turn in the production of TV experiences (Holmes, 2004; Lee, Heeter \& LaRose, 2010; Jenkins et al, 2013). A growing proportion of shows now offer their viewers the chance to be active participants rather than passive recipients in the drama. Traditional TV shows were largely closed off to the viewing public. Until recently, 'broadcasting' meant transmitting a one-way signal to audiences, with no means of receiving a response. Recently, standardisation and integration of digital networking have enabled more immediate 'return path' communication from audiences back to show producers and in some cases direct input to programmes.

Viewer input is more than a technological curiosity. It is driven by market conditions that favour live, spectacular events intended to draw in viewership spread increasingly thinly across a range of media channels (Ytreberg, 2009; Doyle, 2010). The impact of this strategy on networks has been remarkable, with 'interactive' shows now dominating the schedule. For example in the UK in the year 2012, excluding Coronation Street and Downton Abbey, five of the top seven shows involved some form of interactivity: The $X$ Factor, Strictly Come Dancing, Britain's Got Talent, I'm A Celebrity (Get Me Out Of Here) and a new interactive smash-hit: The Voice (Guardian, 2011; Guardian, 2012). Each of these programmes included audience feedback - usually in the form of voting - as an integral aspect of the format. These programmes also incorporate audience discussion and feedback in the post-transmission, cross-platform promotional effort.

While these 'interactive' shows deploy familiar narratives and tropes, the examples provided are qualitatively distinct from traditional programmes. Narratively, they are not closed off to the audience. Instead, the audience is enjoined as part of the coproduction of the televisual event - voting for their favourite contestants and even becoming contestants themselves. While media scholars have rightfully pointed out that much of this interactivity remains superficial, and is carefully managed by show 
producers within highly scripted contexts, the tendency to afford greater control to audiences appears to be accelerating (Jenkins, 1992; Cover, 2006).

The importance of understanding the implications of this transformation is precisely related to the reluctance of show producers to advance beyond cosmetic implementations of interactivity in the first place - greater audience participation brings increased complexity and risk. Legal and regulatory issues abound, and primary among these is the risk surrounding ownership of intellectual property (IP). If audiences are given greater control and input over narrative elements of a show, not only the locus of control but also the right of ownership shifts from producers and broadcasters toward audience contributors. For example, the widespread success of a short clip of Britain's Got Talent contestant Susan Boyle in 2009 prompted a dispute between rightsholder ITV and the online intermediary YouTube over monetisation and revenue sharing from the online circulation of the content. Propelled by the actions of fans, who linked, shared and commented on the clip, the broadcaster was unable to recuperate what it perceived to be fair compensation for the use of the programme's material, with ITV executive chairman Michael Grade describing YouTube's revenue offer as 'derisory' (Guardian, 2009). Despite the capability to block the online circulation of the clip as copyright owners, the broadcaster and production company nevertheless allowed the content to circulate online, perhaps to capitalise on the brand value of the content via other means. Other disputes have involved the appropriation of social media content by broadcasters. In 2009, basketball team owner Mark Cuban complained that ESPN had collected and published a selection of his personal tweets without permission and questioned whether that use constituted copyright infringement ${ }^{1}$. In 2011, an author named Teddy Wayne complained publically that plot elements of an episode of CSI:NY were taken from one of his blog posts without his permission (D'Addario, 2011). Disputes such as these suggest that intellectual property ownership is already a potential site of disagreement between producers of television and online user communities, a terrain that is likely to become more intensely contested as more interactive features are brought into television.

The implications of increased audience input to the production process are profound because intellectual property is at the heart of the TV business. Broadcasters and

\footnotetext{
${ }^{1}$ It is unlikely that a single tweet would meet the threshold of originality required to attract copyright protection in the UK. However, a series of tweets, arranged in a narrative, could constitute an original literary work.
} 
production companies fight over IP ownership, often vigorously, and new divisions are created to exploit it (Endemol, 2010; Sabbagh, 2011). The most valuable IP can be extremely profitable: in a typical year, just 1\% of Endemol's 1,200 formats generate over $50 \%$ of the company's revenue (Aris \& Bughin, 2010). These properties are valuable not only because a show can be sold to multiple territories, but also because a TV-originated brand need not be restricted to TV. Among media professionals, the term 'IP' is considered synonymous with the term 'brand' - it unites distinct manifestations of a core set of ideas (Ytreberg, 2009). This non-legal understanding of IP is often incompatible with legal definitions. For example, in the UK copyright does not protect ideas (such as those constituting a format or brand) but only expressions. Once an expression is made 'fixed', copyright automatically resides in that work. Individual fans, when creating derivative works or when adding creative content to a televisual experience, may themselves own copyright in their new work.

Understanding this dilemma is a key challenge for managers of media businesses, and will become increasingly important as interactivity becomes more widespread. This article identifies discrepancies in existing television industry definitions of interactivity and intellectual property and offers a shared model of intellectual property ownership as a potential solution.

\section{Interactivity}

Before continuing on to describe models of interactive TV production, it is necessary to define more clearly what we mean by 'interactivity'. There are two main lines of scholarly critique that complicate the notion of interactivity in converged, digital media. Firstly, recent critical work has drawn attention to ambiguity of the meaning of the term interactivity at a time when the label has been applied to a diverse array of practices and texts (Kiousis, 2002; Cover, 2006). Second, following initial enthusiasm for the opportunities presented by technologies dubbed Web 2.0 or participatory media, a growing number of scholars have drawn attention to the potentially exploitative relationship between commercial media services and the users that freely contribute their immaterial labour to the benefit of platform owners (Cohen, 2008; Petersen, 2008; Zwick et al, 2008; Martens, 2011). 
Definitional critiques of interactive media have focused on the extent to which features allow users to pass beyond superficial play to effect more profound control over the "author-text-audience relationship" (Cover, 2006). In popular terms, interactivity is used to denote a certain type of new media that differs fundamentally from 'old' media in that it offers new opportunities to engage with its content or engage with others. However, we might usefully conceive of different definitions of interactivity on a spectrum characterised by a relatively low user control at one end, with higher user control at the other. Conversely, one end of the interactive spectrum offers experiences that have been carefully and consciously designed, while media that offer the maximum degree of user interaction are those in which the designers are prepared to relinquish the greatest amount of control over the text.

Definitions of interactivity in which designer control is retained include in which a users input is required in order for the media experience to proceed, or when affordances are given for choice. This definition includes the kind of interactivity found in a branching video game or an interactive novel (Heeter, 2001; Green, 2002).

A second definition of interactivity describes that where there is communication (feedback) between the system and its users, or where users are able to communicate and socialize with other users (McMillan, 2002; Kiousis, 2002). Examples might include a tabletop role-playing game or a social network. In these systems, users are granted more control over the experience, inasmuch as user-touser communication is unpredictable, and their interactions shape the outcome of the experience.

A third type of interactivity, in which the user claims a maximum amount of control, occurs when "the text or its content is affected, resequenced, altered customized or re-narrated in the interactive process of audiencehood" (Cover, 2006:140). This type of interactivity might be intended, for example in cases where openness or gaps are purposefully left in a text to encourage multiple interpretations or readings (Fiske, 1987; Mittell, 2009). Alternatively, this type of interactivity might also emerge from unintended or unauthorized appropriations of messages by fans (Jenkins, 1992; Cover, 2006).

Broadly, these definitions fall under three types: technological design, communication setting, and perceiver experience. We therefore follow Kiousis (2002) who defines interactivity polysemically as: 
[T] he degree to which a communication technology can create a mediated environment in which participants can communicate (one-to-one, one-to-many, and many-to-many), both synchronously and asynchronously, and participate in reciprocal message exchanges (third-order dependency). With regard to human users, it additionally refers to their ability to perceive the experience as a simulation of interpersonal communication and increase their awareness of telepresence. (2002:372).

It is clear that interactivity occurs across a range of different mediums and involves different practices and different relationships between authors, texts and audiences (Cover, 2006).

Given the technological conditions of television as a one-to-many broadcast medium, as well as the historical concentration of television production within a relatively small number of providers, how can we then discuss television, in relation to the definitions provided above, as an 'interactive medium'? John Fiske (1987) was perhaps the first to suggest the radical potential of TV as a site of interactivity, or what he termed 'semiotic democracy'. Borrowing from Roland Barthes, Fiske argued that televisual texts, at least by the 1980s, were 'producerly', suggesting that unlike other mediums, television was not closed to audiences, and that even before the advent of digital return-path mechanisms, TV invited audience participation in ways not accomplished by other mass entertainment (1987:95). Following from Fiske, Jenkins (1992) argued that for much of their history, television broadcasts had been closed to audience participation, but that due to the growth of organised fandoms facilitated by digital technologies, certain television programmes were being opened up to certain kinds of authorised and unauthorised co-production. Intellectual property in particular was a key point of conflict between property owners and audiences in these early forms of interactive appropriation, argues Jenkins because fans, "undaunted by traditional conceptions of literacy and intellectual property [...] raid mass culture, claiming its materials for their own use, reworking them as the basis for their own cultural creations and social interactions." (1992:17). Recently, Jenkins et al (2013) have re-explored the terrain, suggesting that one key attribute of commercially successful media in recent years is that it be "spreadable", that is, adapted to the needs of circulation by both audiences and traditional producers as binary distinctions separating those roles have blurred (2013:7). 
While remaining cautious about applying the interactive label to a heterogeneous group of media experiences, we can propose a framework for identifying interactive elements that may be present in television broadcasts. For example, interactivity in TV shows might be mapped according to the frequency of input and the impact of viewer contributions on the narrative (figure 1). Interactivity in The $X$ Factor occurs with low frequency but with high impact: once a week, during the two or more hours the show is on-air, the public decides who should progress. Football Focus has lowfrequency, low-impact interactivity: occasionally viewers' tweets are read out, and only some of them inform the studio discussion. The Million Pound Drop offers highfrequency, low-impact interactivity: viewers can give their answers to every question faced by the contestants; those answers may be used to create editorial content, but do not affect the course of the show. High-frequency, high-impact shows tend to appear on niche channels but, like Smart Live - Interactive Roulette, they focus entirely on the actions of viewers who are playing along at home.

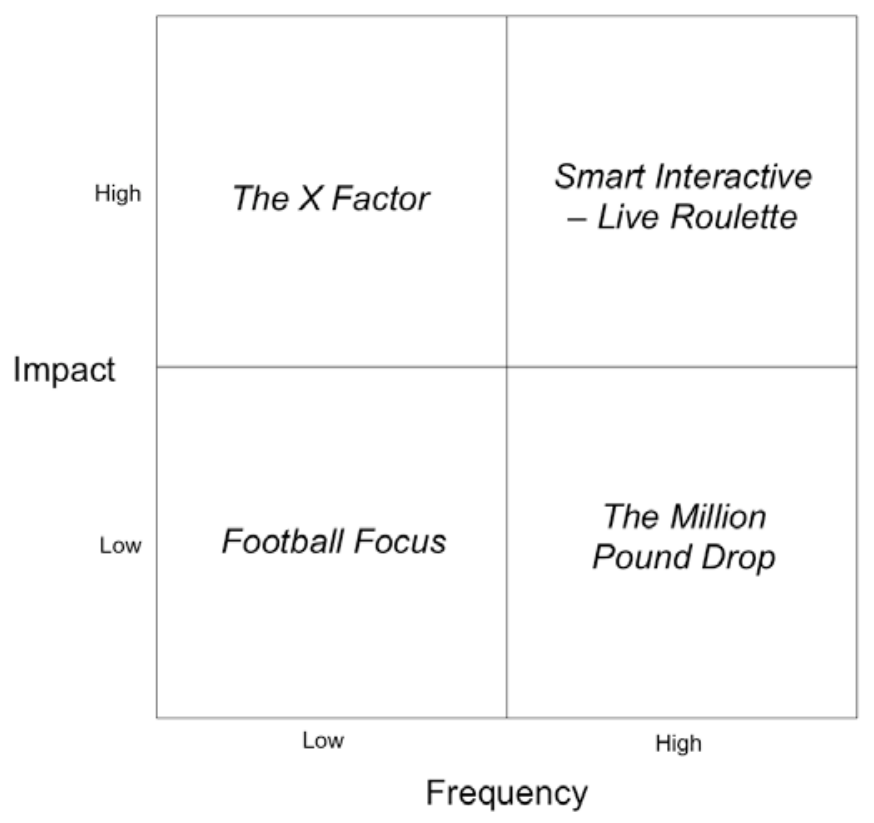

Figure 1: Interactivity matrix for TV shows

Interactivity in TV now occurs in many forms and on many platforms: voting via telephone and SMS, commenting on Facebook and Twitter, and playing along through bespoke websites and apps. 
Siapera (2004) doubts the extent to which the incorporation of interactivity marks a discontinuity with traditional shows. Such doubts are rejected here: instead, a binary distinction is drawn between shows that include interactivity ('interactive shows') and those which do not ('traditional shows'). We have chosen this binary in order to highlight the impact of user contributions - whether frequent or infrequent, significant or trivial - on the overall relationship between show producers and audiences. Specifically, we aim to identify the specific impact of viewer contributions on the production process, insofar as television programmes constitute intellectual property.

\section{Description of research methods}

The authors employed an inductive research approach that focused on interactive television production practices in the UK, using data obtained from confidential interviews carried out with TV production managers as well as information about production practice available in the public domain.

Five interviews with senior executives and production managers were initially conducted by one of the authors. The author worked as an employee embedded inside a large UK TV production company from 2009 to 2013. The interviews took place over the course of one month in 2012. Each interview lasted 40-60 minutes, and took place in the company's main offices.

Interview subjects were judged to have strategic importance within the business and were selected in order to represent the major divisions within the company. All were known to the author as executives who had worked extensively with interactive TV programmes and with issues relating to intellectual property.

The structure of each of the initial interviews was as follows: (1) disclosure of the subject and purpose of the interview; (2) discussion of the individual and company's approach to intellectual property; (3) discussion of interactivity's role in the current UK TV industry; and (4) specific questions relating to each interviewee's area of specialisation.

From these initial interviews in situ, it became apparent that subjects were using multiple definitions of 'IP' when talking about potential challenges to fully implementing interactive elements in existing and upcoming productions. From that 
initial set of qualitative data, the authors developed the proposition that at least 3 separate definitions of IP circulated within the company management: legal, entrepreneurial and accounting.

From 2012 to 2013, the authors conducted an additional 6 interviews outside of the company, with managers from other UK production companies and broadcasters. The role of each of the interview subjects were: 2 production managers from major broadcasters, 2 executives from large media production companies and 2 managers from small (<10 employees) media companies, all working in the TV broadcast and interactive space. These interviews followed a similar semi-structured format and were carried out at the Creative Skillset offices in London. These additional interviews allowed the authors to revisit and refine the initial definitions of IP and add a fourth definition to the model: communitarian.

The following section describes the model developed from both the interviews as well as supplemental data gathered from the public domain about the production practices of UK media companies, including the nature of programmes made since 2012 as well as the legal terms and conditions surrounding audience participation in those programmes.

\section{IP in the context of TV: four models}

This article considers four models of IP: legal, entrepreneurial, accounting, and communitarian. These four models were developed through interviews with key television executives at five UK television production companies, as well as two major broadcasters between 2012 and 2013.

\section{3a. Legal}

The legal model understands IP in terms of the core legal rights of IP ownership, such as copyright, trademarks, and patents. Copyright, which automatically resides in fixed expressions such as television broadcasts, is the form most applicable to TV production. Trademarking protects the show logos and visual designs, so its scope is limited but it is often used by TV companies to protect their products and brands. Patents are rare in the TV industry. The legal view of IP is comparable with physical 
property, in that "[it] can be mortgaged, sold [and] rented... and [the owner has] certain rights to prevent others from making use of [it] without permission" (Oppenheim,1999:5). A legal model of IP encourages a production company to focus on securing rights and preventing infringement above all else.

(i) IP ownership: consumer IP coexists with production company IP

In traditional TV shows, the core elements of the IP are owned initially by the production company (Lessig, 2004). Those elements are mostly copyrights in fixed expressions, such as the specific scripted elements that make up the structure of the show, written materials that have been created by the production team, and the video recording of the show, licensed to a broadcaster. There are likely also trademarks if the production company has registered its ownership of logos and other visual elements.

It is important to note that IP rights have been crafted by legislators to grant a limited monopoly to use and exclude others from the use of an intellectual property. In trademark this has been achieved by limiting the scope of registration only to marks that are distinctive and lie outside of generic language available for use by all traders in the course of commerce. In copyright law, copyrights protect only fixed expressions and not ideas themselves. In order for copyright to attract to a work, the work must meet a threshold of originality and creative input by an author. Consequently, some interactive content will sit outside of formal copyright protection. This could include facts (such as the score in a football match) as well as the ideas that underpin a given TV format. In that sense it is important not to conflate a legal approach to IP with a 'closed' approach to managing interactivity, since in fact the legal approach is preoccupied with locating the - often ambiguous - boundary between protectable and unprotected expression.

In interactive shows, formal copyrights and trademarks are normally held by the production company. But within the framework created by this production company, there will also be consumer contributions - such as viewer comments that appear on-screen during a debate show as in The Big Questions - and those contributions remain the property of their creators. This is made explicit in the terms and conditions of all major UK broadcasters (ITV, 2007; BBC, 2011; Channel 4, 2011; Sky, 2011). Consumers are deemed to have accepted the terms in the act of submitting a contribution. The terms typically grant to the broadcasters - and so, by extension, to 
the production companies to whose shows the contributions are made - a perpetual, non-exclusive, worldwide licence to use and modify them. But consumers retain ownership of their contributions. Interactive shows therefore contain both IP owned by the production company and IP owned by consumers.

(ii) Contract theory: consumers contribute IP on a different contractual basis

Legally-defined IP rights in the UK include the right to derive income from what has been created (Towse, 2006). For example, Endemol's ownership of the rights in The Bank Job enables them to charge a license fee to Channel 4 for the right to broadcast the show. By contrast, consumers' contributions do not earn them a share in the ownership of those IP rights owned by the production company. The alternative, based on the assumption that consumer contributions are an integral part of the show, would be to grant every contributor a share of the license revenues generated by the programme. Not only would that be difficult to administer; it would also be undesirable for production companies, as it would reduce revenues. Nor is there much evidence that consumers expect any form of financial compensation in return for such contributions (Napoli, 2010).

In traditional TV shows, contracts between the production company and the production crew (such as the presenter, director, and camera operators) are agreed through negotiation, are usually intended to be complete contracts, and usually fail in fact to be complete contracts because bounded rationality limits the amount of time and effort that either party is willing to commit to negotiation (Caves, 2000).

In interactive shows, the production company contracts not only with the production crew, but also with the consumer-contributors. Consumers contribute to interactive TV shows on a rather different basis to crew members. The contracts with consumercontributors are formed by the show's terms and conditions. Bounded rationality still plays a role: few consumers are willing to spend time or expend effort on considering the terms of the contract, so it is rare for them to read the terms and conditions before submitting their contributions. But unlike production crew contracts, consumer contracts are created instantaneously, at the point at which each contribution is submitted, and they are made separately but identically between the production company and a large number of individual contributors. 
There is one further difference in the contractual basis upon which consumers contribute. Towse (2006) notes that an inalienable and unwaivable moral right - of attribution, integrity, disclosure, and withdrawal - exists within the EU for contributors to copyright-worthy works. This does not apply to traditional shows, in which there are no consumer contributions, but it does apply to interactive shows. We are not aware of any show that systematically credits every single consumer-contributor. As interactivity becomes more widespread in TV, acknowledging contributors' moral rights may become an issue that interactive shows in the EU are required to address.

As consumers contribute IP on a different contractual basis to production crew, interactive shows gain access to legally-defined IP in a different way to traditional shows.

(iii) The purpose of IP rights: interactive shows invert the utilitarian rationale

William Landes and Richard Posner (1989) follow Mill's utilitarian rationale for the existence of statutory IP rights. They argue that the purpose of IP law is to maximise the benefit of creative endeavours to society by balancing two opposing forces: the ability of exclusive legal rights for creators to stimulate cultural production, and the restrictions that those rights can place upon public enjoyment of cultural products (Fisher, 2001).

This rationale for intellectual property fits neatly with traditional TV production. But Landes and Posner's rationale for IP law is inverted by interactive shows. Consumers' legal rights do not stimulate cultural production - those rights can have no effect because the licence granted to the production company is exclusive and not remunerative. Moreover, as a result of user licenses, it is not the consumer-creators who restrict public enjoyment of their work, but rather the licensees - the production companies who decide which contributions should be made public, and which should be discarded. Consequently it appears that for consumer contributions to interactive shows, the utilitarian rationale for IP law has little relevance.

\section{3b. Entrepreneurial}

The entrepreneurial model of IP development emphasises the process of value creation, while de-emphasising legal frameworks that are perceived to be restricting 
or superfluous to the core activity of the business. The entrepreneurial model views IP as a set of core elements that can be manifested in any form. Creative ideas are transformed into a TV show by a production team, and the same IP is turned into a consumer product (e.g. a branded t-shirt) by a commercial team. In this definition, the American Idol IP comprises the brand name, the core brand values (such as aspiration and realising the American Dream), and the visual identity (such as the iconic blue and white logo) - and those elements have been used to make not only a TV show, but also products ranging from an online game to an entertainment experience at a Disney theme park. Therefore the entrepreneurial model is concerned with how IP is used in practice. As such, an entrepreneurial model of IP encourages a production company to structure its operations around the exploitation of IP not only in the form of shows, but also in as many ancillary sectors as possible.

(i) Creation and consumption of IP: interactive shows remove the distinction, but only for a small proportion of viewers

Hesmondhalgh (2007:36) describes "production" (referring to the creation of a traditional show) and "consumption" (meaning watching the show) as "different moments in a single process". Live interactive shows like The Million Pound Drop remove that distinction by enabling consumers to answer questions in parallel with the studio contestants, and by incorporating consumer responses and statistics into the show. From the point of view of the production company, The Million Pound Drop is being created and consumed simultaneously: a proportion of the audience is both contributing answers and watching the show at the same time by submitting answers through the online game. From the point of view of the online players, too, creation and consumption are combined. They are playing and watching simultaneously. Interactive shows deliberately combine creation and consumption as part of the entertainment experience they offer. They intentionally "stretch the... passive/active dichotomy well beyond breaking point" (Ytreberg, 2009:481).

As yet, however, online players are only a small proportion of the TV audience. From the point of the non-playing viewers, consumption continues uninterrupted. The audience of traditional shows is $100 \%$ passive, since they cannot participate directly in the show. But for interactive shows on mainstream channels, that figure only drops slightly, to $90-95 \%$. Any interactive show in which more than $5 \%$ of its audience participates is celebrated as a major success (Monterosa, 2011). 
This creates a paradox: interactive shows transmitted over mainstream channels must cater primarily for non-interacting viewers. Just like traditional shows, they are funded primarily by advertising. The priority for advertisers is to reach a large audience, so consumer contributions must be fitted into the show in such a way as to ensure the continuing entertainment of the non-participants. Enjoyment must not be contingent upon participation.

Higher engagement rates have so far occurred only when interactive shows appear on non-mainstream channels. Such shows (mostly gambling shows like Smart Interactive - Live Roulette, plus home shopping, psychic hotlines, and pornography) act as vehicles for the display of consumer-created contributions. It is paid-for contributions - usually premium-rate phone calls or SMSs - that fund the show, not advertising, so a large but passive audience is less valuable than a small audience that actively participates.

(ii) Conducting the choir: interactive shows add multiple voices, but the production company determines when, how and which voices are heard

As described in section 3a, interactive shows differ from traditional shows by combining production company IP with consumer IP. From a cultural theory perspective (discussed by Hesmondhalgh, 2007), interactive shows might be considered to erode the production company's authority to speak, because they include many other voices. An important aspect of the entrepreneurial model is that the production company retains considerable control over when, how and which consumer voices are heard. That control is usually exercised by the producer. In The Million Pound Drop, it is the producer who selects which statistics from the online game to pass on to the presenter, at what moment to pass them on, and how they should be phrased when announced on screen. Consumer contributions rarely appear on screen un-moderated in any interactive show. Production company IP creates a framework within which consumer IP is managed.

In this respect, traditional and interactive shows are similar. In both cases, the production company has the freedom to shape, channel, amend, use or ignore material when deciding how to make the show.

\section{3c. Accounting}


IP is included on TV production companies' balance sheets increasingly often (Ghafele, 2007). The accounting model views IP as an asset with financial valueeither as a legal intangible asset (e.g. a copyright), or as a competitive intangible asset (e.g. know-how, carried by the format bibles and flying producers) as described by Kretschmer, Singh and Wardle (2009). Like any other asset, TV show IP has a risk profile and can be valued to assess its worth. An accounting model of IP encourages a production company to concentrate on building its value through protecting and developing its IP.

\section{(i) Asset type: still an intangible asset, but interactivity creates customer lists}

In accounting terms, IP is an intangible asset in both traditional and interactive shows. Just like traditional show IP, interactive show IP is comprised of a combination of legal intangible assets (legally-defined IP, in particular copyrights), and competitive intangible assets (entrepreneurially-defined IP, in particular knowhow relating to how to make the show).

However, interactive shows may be able to develop know-how faster and more fully than traditional shows. A traditional show is measured primarily by its audience ratings - the absolute number of viewers, and the proportion of those watching TV at the time watching the show in question. An interactive show can be measured in many additional ways: for example, how many people interacted at any given moment, or how many interactions there were during a certain segment. More ways to measure means more ways to learn what does and does not work. Apocryphally, Richard Curtis was said to have walked the streets of Shepherds Bush during Blackadder broadcasts to see how many people were watching, and whether or not they were laughing (Locke, 2011). Today, the production team on The $X$ Factor can view not only ratings, but also the number of votes for each contestant, the number and nature of Facebook and Twitter comments by viewers, the number of downloads of the show's app, and the number of times users hit the in-app clap-o-meter to express delight or displeasure at what they are watching. Interactive shows enable their producers to learn quickly, building up substantive and in-depth know-how that producers of traditional shows cannot access.

Interactive shows may also have an additional accounting IP asset: consumer data. In accounting terms, consumer data enables the company to contact consumers 
directly. Customer list data might take the form of email addresses or phone numbers; but increasingly it consists of Facebook Likes or twitter followers. ${ }^{2}$ Customer lists are classed as a legal intangible asset, so interactive shows that capture consumer data may be weighted more heavily towards legal intangible assets in terms of their accounting IP. Customer lists for TV shows are growing in size and importance. For some shows they can reach a considerable size: the Facebook page for the UK version of The $X$ Factor currently has over $6.7 \mathrm{~m}$ Likesaround 50\% of the show's TV audience (The X Factor, 2013). David Abraham, chief executive of Channel 4 , has announced that he believes that audience data - such as the data gathered through shows' Facebook pages - can reinvent TV advertising and inform programme commissioning (Curtis, 2011). Sponsorship of a major UK show's Facebook page now adds to the sponsorship fee, whereas previously it was included in the sponsorship package at no additional cost. Traditional shows are less able to collect consumer data; interactive shows are arguably better-positioned to add customer lists to a production company's balance sheet.

(ii) Risk profile: no inherent change in capital risk, but an increase in consumer touchpoints means an increase in reputational risk

There are two types of risk affecting accounting IP. The first is capital risk. Capital risk derives from the lack of certainty of success, which can be substantial for TV show IP $-80 \%$ of first-run primetime shows on US television are not renewed for a second series (Aris \& Bughin, 2010). Both traditional and interactive TV programmes require a capital outlay on behalf of the production company (which typically funds the development of the initial idea) and, if the show is commissioned, the broadcaster (which funds the production). The level of risk capital required for interactive shows varies greatly, as it does for traditional shows - an inexpensive programme might cost $£ 20$-30k per broadcast hour, but the most expensive exceed $£ 1 \mathrm{~m}$. Interactivity does not necessarily impact production costs: if a bespoke system for managing consumer interactions must be built there will be substantial investment in technology, but such a system is rarely necessary. Most shows use third-party platforms to gather and pass the most pertinent posts on to the presenter through their earpiece. Therefore the capital risk associated with interactive shows cannot be differentiated from that associated with traditional shows.

\footnotetext{
${ }^{2}$ When a consumer 'Likes' a Facebook page or follows a user/brand on Twitter, they will receive messages posted by that user/brand.
} 
The second form of risk affecting accounting IP assets is reputational. Reputational risk is inherent in the deployment of the asset. Each time the asset is deployed, either in an episode of the TV show or in a consumer product, the asset comes into contact with consumers, and the way they perceive it affects its value. Each touchpoint between a show and a contributor entails a reputational risk: if the tone is misjudged, the information displayed is inaccurate, or the experience of participation is in any way unenjoyable, the show suffers reputational damage that affects the value of its IP. That damage manifests itself on the balance sheet when consumers engage with the show less frequently or not at all, and the IP valuation is reduced.

\section{(iii) Brand valuation: no inherent change}

Salinas and Ambler's (2009) analysis of brand valuation methods identifies three popular approaches. The first is the cost approach, which values the brand on the basis of the cost of creation. This approach is analogous to the assessment of capital risk; as discussed above, the addition of interactivity does not inherently change the valuation applied to a TV brand. The second is the market approach, which relies on the sales price of comparable brands; since TV formats are very rarely bought and sold between companies, there is insufficient data to identify any difference between traditional and interactive show brand valuations in this respect. The third approach is based on income: it values brands according to their projected future earnings, usually using a royalty relief rate. There is no reason to expect that interactivity necessarily adds to the future earnings potential of a TV show. Therefore interactivity cannot be expected to make a difference when valuing TV IP by any of these three methods.

\section{3d. Communitarian}

The communitarian model suggests that IP belongs not only of the individual or small group working directly on the project, but also of the shared culture from which that individual or group draws its ideas, understanding and inspiration, and to which many others in that culture contribute. The notion that all creation is, to some extent, cocreation makes the communitarian model important to this discussion. The key components of the communitarian model should be more visible in interactive shows than they are in traditional shows, because the former use interactivity to encourage and facilitate co-creation, and the latter do not. In this definition, IP is regarded as 
different to physical property because it has the qualities of what economists describe as a 'public good' - when one person consumes it, it does not become less valuable or available to others (Lessig, 2004; Hesmondhalgh, 2007). Were a production company to adopt a communitarian model of IP, it might wish to explore ways of sharing the credit for, ownership of, and even the financial rewards from any co-created IP.

(i) Public goods: some interactive shows are less well described as public goods than others

Legal scholar Lawrence Lessig argues that many cultural products are best compared to public goods because their consumption does not reduce the value or availability of the good to subsequent consumers (Fisher, 2001; Lessig, 2004; Hesmondhalgh, 2007). While most TV programmes could be defined as public goods by virtue of being non-rivalrous and non-excludable, not all interactive experiences can be thus described. For example, You're On Sky Sports is a football talk show which invites viewers to send SMSs and tweets in order to participate in a debate with the on-screen pundits. Only a limited number of SMSs and tweets are displayed on screen, and only those displayed on screen are part of the debate. The $10 \%$ of consumer messages that appear on screen are there in place of any of the other $90 \%$. So You're On Sky Sports is an example of an interactive show that does not meet the test for being a public good as fully as traditional TV shows do: the consumption of one element of the experience reduces the availability of the good for subsequent consumers.

(ii) Meta-texts: both show types can create communitarian IP, but interactive shows do so much more frequently

There have long been creative consumer contributions to cultural products - Jenkins (1988) examined the efforts of Star Trek fans to create a wide variety of materials or 'paratexts' relating to the show. Now, using the Internet, consumers with shared interests can more easily bond together into larger, more geographically widespread, and more organised groups (Shirky 2008). Jenkins (1992:284) further discussing the 'meta-text[s]' created by fans of popular TV series, describes them as "a collaborative enterprise [which] effaces the distinction between reader and writer, opening the programme to appropriation by its audience". An interactive show 
creates a collaborative meta-text by default, because both the production company and consumers are involved in the show's production. In traditional shows such as Star Trek, the meta-texts are usually not generated collaboratively.

However, there are increasing instances of a production company working with consumers on collaborations related to a traditional show. In 2011 a mash-up artist called Swede Mason created a wildly popular music video using clips from Masterchef, which by May 2013 had $6.4 \mathrm{~m}$ views on YouTube. Masterchef is produced by Shine, so most of the legal IP rights in the constituent clips are theirs. But instead of requesting that the video be removed from YouTube, Shine gave retrospective permission to Swede Mason to use the clips, partnered with his record label, and released the song as a single on iTunes. It went to number 37 in the UK charts and generated revenue for all three parties (Codrington 2011). So both traditional and interactive shows can create communitarian IP, but only the latter do so automatically - for traditional shows to do so requires additional effort.

(iii) Meta-texts: interactive shows dissolve three boundaries

Interactive shows dissolve three boundaries relating to the creation of meta-texts that exist in traditional shows. First, aside from rare exceptions such as the Masterchef song collaboration, it is only interactive shows that turn the audience (Jenkins's "readers") into producers - doing so effaces the distinction between reader and writer. Second, only interactive shows can turn the producers (Jenkins's "writers") into the audience, passively receiving contributions from consumers (Cover 2006). And third, only interactive shows' meta-texts actually appear on the screen, as part of the TV show. Interactive shows dissolve three boundaries that exist in traditional shows: the audience become producers, the producers become the audience, and the meta-texts appear on-screen.

\section{Conclusions: a new approach for interactive TV production?}

In the preceding discussion we have hoped to advance two modest claims. First, we propose that IP is currently understood in different and potentially contradictory ways by media business managers, depending on the operation in question or the position of an observer within a company: lawyers, accountants, audiences and entrepreneurs all define IP differently. Second, we wish to highlight that one's starting 
position necessarily impacts how one weighs the costs and benefits associated with viewer contributions. A legal expert may focus on whether an end-user license agreement is sufficiently robust to override any future copyright claims that a contributor may have in a work; a producer may be more interested in whether a contribution adds value to the content of a show. Importantly, no one model is sufficient to fully grasp the complexity added by viewer contributions - legal, entrepreneurial, accounting and communitarian definitions would ideally all be taken into account when weighing the benefits and risks of designing an interactive TV show.

On balance, our discussion suggests that formal legal definitions of IP may be particularly inadequate to strategic planning and management in this space. A purely legal protectionist view of content as property may have been suitable to noninteractive TV programmes, but the introduction and intensification of audience interactivity poses challenges for the traditional legal paradigm: what aspects of proprietary content should be allowed to circulate outside of the hands of producers? What value is potentially generated by enabling user-contributions and at what potential cost? Since the legal right alone does not appear to incentivise user contribution, and since copyright places restrictions on where audiences might further transmit or share the fruits of their creative labour, a copyright-centric approach may not be entirely fit for purpose.

The current consequence of adopting one or more of these contradictory definitions of IP is significant for managers of interactive productions incorporating different stakeholders (producers, intermediaries, and audiences). For example, a business that adopts an overly strict and risk-averse approach to content ownership by prioritising the legal conception of IP may prejudice the "spreadability" of their media content in other channels (Jenkins et al, 2013). Fickle audiences may detect insincere attempts to foster interactivity in TV experiences without feeling empowered to influence the content as co-participants. On the other hand, innovators that adopt communitarian modes of interactivity may be unprepared to adequately protect and account for the value of their own IP content and preserve the sustainability of their creative output.

We suggest that an alternative approach may be for producers and broadcasters to view interactive TV as a platform. As opposed to characterising a TV programme as content or as a 'text', platforms are spaces into which users are invited, where their 
contributions are solicited and facilitated, and in which collaborative creations can be undertaken for the mutual benefit of the platform owner and the consumercontributors. The platform approach is different from previously discussed communitarian approaches to IP because while the ownership of any given piece of content is relaxed in both cases, the platform owner has the privileged position of shaping the social rules and norms as well as the technological conditions of circulation of content within the circumscribed boundaries of the platform. In this sense, the producer/owner takes on the role of curator, rather than author, sidestepping issues of IP ownership while potentially introducing new and different challenges ${ }^{3}$.

The most prominent interactive media successes of recent years have been examples of such internet-powered platforms. Among them are Twitter and Facebook, which have amassed $200 \mathrm{~m}$ and $1.1 \mathrm{bn}$ monthly active users respectively (Etherington 2012, Olanoff 2013). ${ }^{4}$ Both Twitter and Facebook deal with consumer contributions in the same way. Consumers input information, and that information is given context and meaning by the framework that the platform owner has created. For example, if a consumer types an update into Facebook on what they have been doing today - such as 'I've been writing my article!' - that input means little in isolation. But Facebook's platform connects consumers who know one another - so the update is seen by the consumer's friends. If a friend chooses to comment on the update, the update gains greater prominence on the homepages of the consumer's friends - so more interesting or amusing updates will gain greater prominence over time. The contribution from the consumer is simple - just like a contribution to an interactive TV show. It is the way the contribution is handled by the platform that turns it into something useful, interesting, or entertaining - again, just like an interactive TV show.

The four definitions discussed above continue to be salient but are transformed by the approach of treating interactive TV programmes as platforms:

\footnotetext{
${ }^{3}$ Paramount among the challenges is the obligation of platform owners to respond to libellous or infringing content generated by users. Under the European e-Commerce Directive $2000 / 31$, intermediaries are required by other rightsholders to remove infringing content from their platforms expeditiously upon notification and must therefore devote resources to excising, moderating and policing the contributions of users.

${ }^{4}$ Both define 'monthly active users' as those who have logged into the service at least once in the past 30 days.
} 
a. Legal: the platform owns the copyrights, trademarks, and perhaps software patents in the technical framework, but consumers also own their own contributions via non-exclusive license.

b. Entrepreneurial: consumer contributions are managed and channelled so as to create an engaging experience that responds to market demand and in particular, leverages social networks.

c. Accounting: consumer contributions are not counted as assets, but the platform's framework is comprised of intangible legal and competitive assets that do appear on its balance sheet, including customer data. Both Twitter and Facebook generate the bulk of their revenue by serving adverts to consumers based on the information in their customer lists, so those lists are extremely valuable.

d. Communitarian: both platforms actively encourage outsiders to build new applications on top of the platform IP; for example, by making their APIs (Application Programming Interfaces) available to external developers for free.

It may become the case that interactive TV programmes share more similarities with web platforms than they do with traditional TV shows. Media managers seeking to understand the effects of interactivity on IP are encouraged to move beyond thinking about TV content and online interactivity as at worst, enemies and at best, complementary but exclusive domains. It is likely that the future of interactive TV will not consist of slightly modified versions of traditional shows, but instead incorporate features of both broadcast and interactive platforms.

This paper has identified substantial differences between IP in traditional shows and IP in interactive shows across a range of management priorities. In interactive shows, consumer-contributed IP coexists with, but is not blended with, IP owned by the production company. Instead, consumer IP is added to a framework constructed by production company IP. Currently, legal contracts are established between broadcasters and contributors to secure rights to use that content commercially. However, audiences remain disempowered in their consumption of 'interactive' shows - they do not enjoy the same freedom to appropriate, remix, and share content owned by production companies and broadcasters, potentially limiting the overall audience for these products (Cover, 2006; Erickson, 2013; Jenkins et al, 2013).

New opportunities might be created if production companies viewed themselves not simply as IP owners but also as IP curators and managers. Because of the centrality of social contributions to these programmes, interactive shows may be closer to web platforms than they are to traditional TV shows when it comes to the way that IP 
should be managed. The similarity with web platforms suggests a helpful analogy for TV executives seeking to understand the impact of interactivity on TV IP: programmes as platforms.

\section{References:}

App Annie (2013, April 13). Top Charts: iPhone - United Kingdom - Overall. Retrieved May 3, 2013, from: http://www.appannie.com/top/iphone/unitedkingdom/overall/.

Aris, A., \& Bughin, J. (2010). Managing media companies. Chichester: John Wiley \& Sons.

BBC (2009, November 9). Russell Howard's Good News Extra - answering your questions off Twitter - BBC Three. Retrieved November 29, 2011, from: http://www.youtube.com/watch?v=Hdb39JJLAYA.

BBC (2011, January 10). Terms and Conditions. Retrieved January 4, 2012, from: http://www.bbc.co.uk/terms/personal.shtml\#4.

British Sky Broadcasting Group (2011, February 1). Terms and Conditions. Retrieved January 4, 2012, from:

http://www.sky.com/helpcentre/account-and-billing/terms-and-conditions/.

Bulkley, K. (2010, December 6). The future of TV. Retrieved January 4, 2012, from: http://www.guardian.co.uk/future-tv/guardian-red-bee-future-tv-debate.

Caves, R.E. (2000). Creative industries. Cambridge, MA: Harvard University Press

Channel Four Television Corporation (2011, December 22). Terms and Conditions. Retrieved January 4, 2012, from:

http://www.channel4.com/terms and conditions.html.

Codrington, J. (2011, August 30). Interview: Swede Mason. Retrieved January 5, 2011, from: http://www.thestoolpigeon.co.uk/features/interview-swede-masonmasterchef-synesthesia.html.

Cohen N.S., (2008). The valorization of surveillance: Towards a political economy of Facebook. Democratique Communiqué, 22(1), 5-22. 
Conlan, T. (2011, December 20). X Factor final Pips royal wedding to become mostwatched show of 2011. Retrieved September 8, 2000, from:

http://www.guardian.co.uk/media/2011/dec/20/x-factor-final-royal-wedding.

Cover R., (2006). Audience inter/active: Interactive media, narrative control and reconceiving audience history. New Media \& Society, 8(1), 139-158.

Curtis, C. (2011, May 24). Abraham: data will drive C4. Retrieved January 5, 2012, from: http://www.broadcastnow.co.uk/news/broadcasters/channel-4/abraham-datawill-drive-c4/5028044.article.

D’Addario, (2011, February 22). New York Freelancer: 'CBS Stole My Story-And It Wasn't Even True!' Retrieved 6 April 2014 from: http://observer.com/2011/02/newyork-freelancer-cbs-stole-my-storyand-it-wasnt-even-true/\#ixzz2y6sKeNAr

Davidson-Houston, R. (2011, September 8). Interview with Richard DavidsonHouston, head of Channel 4 Online. Retrieved December 19, 2011, from: http://www.youtube.com/watch?v=HDQZbprtdVU.

Doctorow, C. (2011, December 2). Copyrights vs. human rights. Retrieved December 29, 2011, from: http://www.publishersweekly.com/pw/print/20111205/49728-corydoctorow-copyrights-vs-human-rights.html.

Doyle, G. (2010). From Television to Multi-Platform Less from More or More for Less? Convergence, 16(4), 1-19.

Dredge, S. (2012, October 29). Social TV and second-screen viewing: the stats in 2012. Retrieved May 3, 2013, from:

http://www.guardian.co.uk/technology/appsblog/2012/oct/29/social-tv-second-screenresearch.

Eames, T. (2011, December 22). Channel 4's online game 'Bank Job' played over 2 million times. Retrieved January 5, 2012, from:

http://www.digitalspy.co.uk/tv/news/a357179/channel-4s-online-game-bank-jobplayed-over-2-million-times.html.

Economist (2010, March 29). Changing the channel. Retrieved April 1, 2012, from: http://www.economist.com/node/15980859.

Endemol (2010, March 29). Endemol launches new global brands business.

Retrieved January 4, 2012, from: http://www.endemol.com/news/endemol-launchesnew-global-brands-business.

Erickson, K. (2013). Evaluating the Impact of Parody on the Exploitation of Copyright Works: An empirical study of music video content on YouTube. London: Intellectual Property Office UK. 
Etherington, D. (2012, December 18). Twitter Passes 200M Monthly Active Users, A 42\% Increase Over 9 Months. Retrieved May 4, 2013, from http://techcrunch.com/2012/12/18/twitter-passes-200m-monthly-active-users-a-42increase-over-9-months/.

Fagerjord, A. (2010). After convergence: YouTube and remix culture. In J. Hunsinger, L. Klastrup, \& M. Allen (eds.), International handbook of internet research (pp.187-200). Dordrecht: Springer Science+Business Media.

Fisher, W.W. (2001). Theories of intellectual property. In: S.R. Munzer (ed.), New articles in the legal and political theory of property (pp.168-200). Cambridge, MA: Cambridge University Press.

Fiske, J. (1987). Television Culture. New York: Routledge.

Ghafele, R. (2007). Getting a grip on accounting and intellectual property. Retrieved January 4, 2012, from: http://www.wipo.int/sme/en/documents/ip accounting.html.

Green, L. (2011, August 27). Think tank: social media and TV need not be enemies. Retrieved January 4, 2012, from:

http://www.telegraph.co.uk/finance/businessclub/managementadvice/8725293/Think-Tank-Social-media-and-TV-need-not-be-enemies.html.

Guardian (2009, July 13). ITV's Michael Grade: YouTube's Susan Boyle offer was derisory. Retrieved 5 April 2014 from:

http://www.theguardian.com/media/pda/2009/jul/13/digital-media-susan-boyle.

Guardian (2011, December 20). Top-rating TV shows of 2011. Retrieved September 8, 2012, from: http://www.guardian.co.uk/media/table/2011/dec/20/top-rating-tvshows-2011.

Guardian (2012, December 12). Most viewed TV programmes in 2012. Retrieved May 3, 2013, from: http://www.guardian.co.uk/media/2012/dec/12/most-viewed-tvprogrammes-in-2012.

Hesmondhalgh, D. (2007). The cultural industries. London: Sage

Holmes, S. (2004). But this Time You Choose! Approaching the 'Interactive' Audience in Reality TV. International Journal of Cultural Studies, 7(2), 213-231.

ITV PLC (2007, July 31). Terms and Conditions. Retrieved January 4, 2012, from: http://www.itv.com/termsandconditions/termsconditions/default.html.

Jenkins, H. (1988, June). Star Trek reread, rerun, rewritten. Retrieved December 26, 2011, from: http://web.mit.edu/211.432/www/readings/star trek rerun.pdf.

Jenkins, H. (1992). Textual poachers. London: Routledge. 
Jenkins, H., Ford, S., and Green, J. (2013). Spreadable Media: Creating value and meaning in a networked culture. New York: New York University Press.

Kiousis S. (2002). Interactivity: a concept explication. New Media \& Society, 4(3), 355-383.

Kretschmer, M., Singh, S., \& Wardle, J. (2009). The exploitation of television formats: Overview. Retrieved December 12, 2011, from:

http://tvformats.bournemouth.ac.uk/overview.html

Küng, L. (2008). Strategic management in the media. London: Sage.

Landes, W. \& Posner, R. (1989). An Economic Analysis of Copyright Law. Journal of Legal Studies, 325(18), 344-53.

Lee, M.S., Heeter, C \& LaRose, R. (2010). A modern Cinderella story: a comparison of viewer responses to interactive vs linear narrative in solitary and co-viewing settings. New Media \& Society, 12(5), 779-795.

Lessig, L. (2004). Free culture. London: Penguin.

Locke, M. (2011, November 30). Next on TV: data driven programming. Retrieved August 29, 2012, from: http://www.wired.co.uk/magazine/archive/2011/12/ideasbank/next-on-tv.

Masnick, M. (2009, December 31). Author Robin Sloan offers up money to fans for good remix ideas. Retrieved August 4, 2012, from:

http://www.techdirt.com/articles/20091228/1730047523.shtml.

Monterosa (2011). Work: Million Pound Drop. Retrieved January 4, 2012, from: http://www.monterosa.co.uk/work/mpd.

Napoli P.M., (2010). Revisiting 'mass communication' and the 'work' of the audience in the new media environment. Media, Culture \& Society, 32(3), 505-516.

Olanoff, D. (2013, May 1). Facebook's Monthly Active Users Up 23\% to 1.11B; Daily Users Up 26\% To 665M; Mobile MAUs Up 54\% To 751M. Retrieved May 4, 2013, from http://techcrunch.com/2013/05/01/facebook-sees-26-year-over-year-growth-indaus-23-in-maus-mobile-54/.

Oliver \& Ohlbaum Associates. (2010). Making Money In The On Demand Media Age. London: Oliver \& Ohlbaum Associates.

Oppenheim, C. (1999). The legal and regulatory environment for electronic information. Tetbury: Infonortics. 
Patry, W. (2011, December 27). Copyrights are no longer about copies. Retrieved December 29, 2011, from: http://www.bloomberg.com/news/2011-12-27/copyright-isno-longer-about-copies-part-1-commentary-by-william-patry.html.

Rich, L.J. (2011, November 18). The phenomenon of two screen viewing. Retrieved January 4, 2012, from:

http://news.bbc.co.uk/1/hi/programmes/click online/9640887.stm.

RTL Group (2013, February 25). RTL Group generates strong financial results for 2012. Retrieved May 3, 2013, from:

http://www.rtlgroup.com/www/htm/pressrelease 1A0B526DF91D426C8529F57F7FE DD49D.aspx.

Sabbagh, D. (2011, September 16). X Factor co-producer: BBC Worldwide distorts the market. Retrieved December 22, 2011 from:

http://www.guardian.co.uk/media/2011/sep/16/x-factor-producer-bbc-worldwide.

Salinas G., \& Ambler T., (2009). A taxonomy of brand valuation practice:

methodologies and purposes. Brand Management, 17(1), 39-61.

Screenpop (2011, September 19). Screenpop to launch Intuïtie. Retrieved November 23, 2011, from: http://www.screenpop.co.uk/intuition.html.

Shirky, C. (2008, March 5). Clay Shirky on New Book "Here Comes Everybody". Retrieved January 6, 2012, from:

http://www.youtube.com/watch?v=A 0FgRKsqqU\&feature=youtu.be\&t=1m8s.

Siapera E., (2004). From couch potatoes to cybernauts? The expanding notion of the audience on TV channels' websites. New Media \& Society, 6(2), 155-172.

Swede Mason (2011, June 28). Masterchef Synesthesia. Retrieved May 3, 2013, from: http://www.youtube.com/watch?feature=player embedded\&v=lfeyUGZt8nk.

Sweney, M. (2010, August 16). Peperami to launch crowdsourced ad. Retrieved August 4, 2012, from: http://www.guardian.co.uk/media/2010/aug/16/peperami-adcrowdsourcing.

Sweney, M. (2013, March 26). FremantleMedia set for buying spree. Retrieved May 3, 2013, from: http://www.guardian.co.uk/media/2013/mar/26/fremantle-mediabuying-spree-berteksmann.

The X Factor (2013, May 3). Facebook profile. Retrieved May 3, 2013, from: https://www.facebook.com/TheXFactor.

Thill, S. (2009, May 1). Want a Remix Manifesto? Name your price, says RiP director. Retrieved August 4, 2012, from:

http://www.wired.com/underwire/2009/05/brett-gaylor-talks-rip-remix-manifesto/. 
Towse R., (2006). Copyright and artists: a view from cultural economics. Journal of Economic Surveys, 20(4), 568-585.

Unterberger, A. (2004, July 20). Playing God - Jay-Z: The Black Album. Retrieved August 4, 2012, from:

http://www.stylusmagazine.com/articles/playing god/jay-z-the-black-album.htm.

Ytreberg E., (2009). Extended liveness and eventfulness in multi-platform reality formats. New Media \& Society, 11(4), 467-485. 